\title{
Effect of Bonding Interactions between Arsenate and Silver Nanofilm on Surface-Enhanced Raman Scattering Sensitivity
}

\author{
Zhonghou Xu, ${ }^{\dagger}$ Chuanyong Jing, ${ }^{\ddagger}$ Jumin Hao, $^{\dagger}$ Christos Christodoulatos, ${ }^{\dagger}$ George P. Korfiatis, ${ }^{\dagger}$ Fasheng Li, $^{\S}$ \\ and Xiaoguang Meng ${ }^{*,+}$ \\ ${ }^{\dagger}$ Center for Environmental Systems, Stevens Institute of Technology, Castle Point on Hudson, Hoboken, New Jersey 07030, \\ United States \\ ${ }^{\ddagger}$ State Key Laboratory of Environmental Chemistry and Ecotoxicology, Research Center for Eco-Environmental Sciences, \\ Chinese Academy of Sciences, 18 Shuangqing Road, Beijing 100085, People's Republic of China \\ ${ }^{\S}$ Laboratory of Soil Pollution Control, Chinese Research Academy of Environmental Sciences, Dayangfang 8, Beijing 100012, \\ People's Republic of China
}

Supporting Information

ABSTRACT: The effect of $\mathrm{Ca}^{2+}$ on surface-enhanced Raman scattering (SERS) analysis of arsenate (As(V)) using Ag nanofilm was studied. Extended X-ray absorption fine structure (EXAFS) was used for the first time to investigate the bonding structures of adsorbed As (V) on the SERS substrate, as well as the mechanism of the $\mathrm{Ca}^{2+}$ effect on the SERS analysis of As(V). $\mathrm{As}(\mathrm{V})$ was found to be adsorbed on $\mathrm{Ag}$ nanofilm through

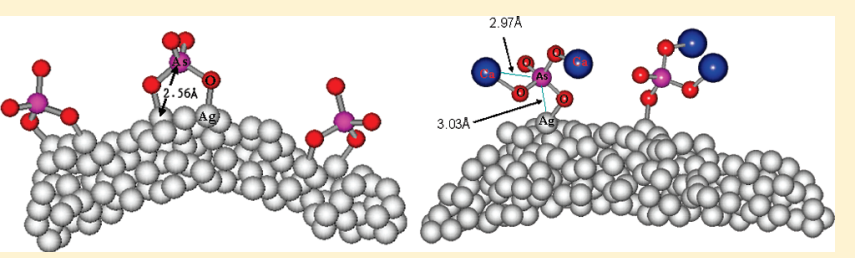
formation of bidentate binuclear surface complexes $(\mathrm{AgO})_{2} \mathrm{AsO}_{2}{ }^{-}$with an average As- $\mathrm{Ag}$ interatomic distance of $2.56 \AA$ in the $\mathrm{As}(\mathrm{V})$ single adsorbate system, and through formation of a ternary surface complex $(\mathrm{AgO})(\mathrm{CaO})_{2} \mathrm{AsO}^{+}$with an average $\mathrm{As}-\mathrm{Ag}$ distance of $3.03 \AA$ in the presence of $\mathrm{Ca}^{2+}$. The formation of the ternary surface complex dramatically decreased the SERS sensitivity and resulted in a shift of the SERS As $(\mathrm{V})$ band from $780 \mathrm{~cm}^{-1}$ for the As(V) system to $790 \mathrm{~cm}^{-1}$ in the As $(\mathrm{V})-\mathrm{Ca}{ }^{2+}$ binary adsorbate system. It was discovered that the negative effect of $\mathrm{Ca}^{2+}$ and $\mathrm{Mg}^{2+}$ was reduced dramatically by addition of $\mathrm{F}^{-}$into As $(\mathrm{V})$ solution and groundwater samples. The fundamental information on the $\mathrm{Ca}^{2+}$ perturbance of surface interactions between As(V) and $\mathrm{Ag}$ will help in the development of SERS techniques for analysis of $\mathrm{As}(\mathrm{V})$ in contaminated groundwater.

\section{INTRODUCTION}

Arsenic is one of the most common inorganic contaminants in groundwater worldwide due to natural and anthropogenic sources. ${ }^{1}$ Although a number of laboratory instruments are used for accurate measurement of arsenic in environmental samples at microgram per liter concentrations, there is still a necessity for development of simple and rapid methods for field assays. A feasible promising route for field analysis of arsenic is to develop a highly active substrate for surface-enhanced Raman scattering (SERS) of arsenic that can be used in conjunction with portable Raman technology. ${ }^{2}$

Recently, Mulvihill et al. ${ }^{3}$ and our group ${ }^{4}$ used Ag nanoparticles for sensitive SERS analysis of arsenic species at the low microgram per liter level in solutions. In our study, Ag nanofilm was prepared on glass slides with a modified mirror reaction, and the SERS analysis was conducted by transferring $10 \mu \mathrm{L}$ of arsenic solutions onto the nanofilm followed by recording the SERS spectra with a Raman spectrometer. ${ }^{4}$ The results suggest that SERS offers great promise for the development of sensitive, rapid, and portable techniques for analysis of arsenate $(\mathrm{As}(\mathrm{V}))$ and arsenite (As(III)) species. However, we also observed that $\mathrm{Ca}^{2+}$, a common cation in natural waters, significantly reduced the sensitivity of SERS analysis.
The extremely high sensitivity of SERS ${ }^{5,6}$ is widely attributed to the electromagnetic enhancement (EM) effect and chemical enhancement (CE) or charge transfer effect. ${ }^{7,8}$ While the EM effect is primarily caused by the local electric field around the adsorbed molecules, the CE effect requires direct proximity or chemical bonding between the molecules and the surface metal atoms. It has been reported that SERS sensitivities are related to the adsorption affinity and surface orientation of analytes for the metal nanosurface and to the distance between the analytes and the surface. ${ }^{9-12}$ However, no bonding structures of analytes on the SERS active surface have been measured directly. The lack of this crucial information prevents accurate theoretical calculations of the CE factors. ${ }^{13-17}$

Extended X-ray absorption fine structure (EXAFS) is a wellestablished and powerful spectroscopic technique to determine local structural information for adsorbed species on mineral surfaces. ${ }^{18-20}$ We have used the technique to determine the bonding structures of adsorbed arsenic species on iron and titanium oxides. ${ }^{21}$ In this article, EXAFS was used to directly

Received: September 14, 2011

Revised: December 7, 2011

Published: December 30, 2011 
determine the bonding structures of $\mathrm{As}(\mathrm{V})$ on $\mathrm{Ag}$ nanofilm and the mechanism of the $\mathrm{Ca}^{2+}$ effect on the intensity and position of the SERS As (V) band.

\section{EXPERIMENTAL SECTION}

The Ag nanofilm was prepared using a modified mirror reaction ${ }^{4}$ and was used as the SERS substrate. Briefly, $18 \mathrm{~mL}$ of a 2 wt $\% \mathrm{AgNO}_{3}$ solution was put into a Coplin staining jar, then $20 \mu \mathrm{L}$ of $3.2 \mathrm{wt} \% \mathrm{KOH}$ solution was added into the $\mathrm{AgNO}_{3}$ solution. The solution was mixed with a magnetic mixer to form a fine brown precipitate of $\mathrm{Ag}_{2} \mathrm{O}$. Then, ammonium hydroxide (29.5\%), $\mathrm{AgNO}_{3}$ (6 wt \%), and ammonium hydroxide (6\%) solutions were added into the solution sequentially to form $\mathrm{Ag}\left(\mathrm{NH}_{3}\right)_{2}{ }^{+}$. The solution was mixed with $3 \mathrm{~mL}$ of methanol, $10 \mu \mathrm{L}$ of 10 wt $\% \mathrm{Na}_{3} \mathrm{P}_{5} \mathrm{O}_{10}$, and $40 \mu \mathrm{L}$ of 5 wt $\% \mathrm{Na}_{2} \mathrm{HPO}_{4}$ consecutively to form a yellow colloid. Then, $6 \mathrm{~mL}$ of $35 \mathrm{wt} \%$ glucose was added and mixed. The glass slides (cleaned in Piranha solution) were immersed in the colloidal suspension for an hour at $20^{\circ} \mathrm{C}$ to form $\mathrm{Ag}$ nanofilm on them. Finally, the substrates were taken out and rinsed with DI water. All the chemicals used were certified ACS grade and were purchased from Fisher Scientific, Inc.

The surface morphology of the resulting Ag nanofilm was characterized by atomic force microscopy (AFM, Digital Instrument nanoscope). AFM images were obtained in the tapping mode and using Olympus OTESP tips at a scan rate of $2.543 \mathrm{~Hz}$.

SERS analysis was performed by transferring $10 \mu \mathrm{L}$ of solution samples onto the SERS substrate. SERS spectra of As(V) were obtained using a Nicolet Almega XR dispersive Raman spectrometer with a laser source at $780 \mathrm{~nm}$ and $35 \mathrm{~mW}$. Each analysis was performed with 10 exposures, 3 s each exposure, and $25 \%$ of the laser power.

The effect of $\mathrm{Ca}^{2+}$ on $\mathrm{As}(\mathrm{V})$ adsorption on $\mathrm{Ag}$ nanofilm was tested by transferring $250 \mu \mathrm{L}$ solutions containing $5 \mathrm{mg} / \mathrm{L} \mathrm{As}(\mathrm{V})$ and $0-10 \mathrm{mg} / \mathrm{L} \mathrm{Ca}{ }^{2+}$ onto the nanofilm. $\mathrm{Ca}\left(\mathrm{NO}_{3}\right)_{2}$ was used to prepare the $\mathrm{Ca}^{2+}$ stock solution. The adsorption time was $10 \mathrm{~min}$. The As(V) concentration before and after adsorption was analyzed by a Graphite furnace atomic adsorption spectrometer (GFAAS) (Varian Spectra AA-220Z).

For EXAFS experiments, $50 \mu \mathrm{L}$ of $\mathrm{As}(\mathrm{V})$ and $\mathrm{As}(\mathrm{V})-\mathrm{Ca}^{2+}$ solutions $\left(\mathrm{As}(\mathrm{V})=5 \mathrm{mg} / \mathrm{L} ; \mathrm{Ca}^{2+}=10 \mathrm{mg} / \mathrm{L}\right)$ were dropped on Ag nanofilms (about $1 \mathrm{~cm}^{2}$ ). After the samples dried, the EXAFS spectra of adsorbed arsenate on the silver nanofilm were collected at room temperature and under a helium atmosphere on beamline $\mathrm{X} 18 \mathrm{~B}$ at the National Synchrotron Light Source (NSLS) in Brookhaven National Laboratory. An energy range of -200 to $1000 \mathrm{eV}$ from the K-edge of As $(11868 \mathrm{eV})$ was used to acquire the spectra. All spectra were collected in fluorescence mode using a 13 element energy dispersive Ge detector. An average of three scans was collected to achieve an adequate signal/noise ratio. The EXAFS spectra were analyzed using the Athena and Artemis program in the IFEFFIT computer package. ${ }^{22}$ The general approach was the same as that used in a previous study on EXAFS measurement of adsorbed arsenic on iron, titanium, and aluminum oxides. ${ }^{23}$ Individual spectra were first averaged, and backgrounds were subtracted with a linear function through the pre-edge region. The averaged spectra were normalized to the atomic absorption, and the EXAFS signal was extracted from the spectra. Then, the data were converted from energy to photoelectron momentum ( $k$ space) and weighted by $k^{3}$ to account for the dampening of oscillations with increasing $k$.

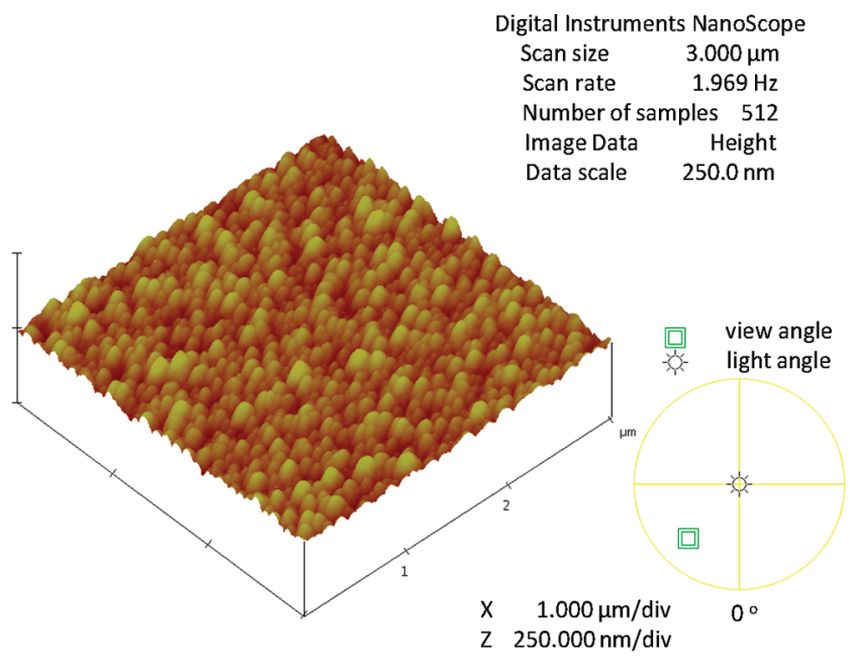

Figure 1. AFM image of Ag nanofilm.

Fourier transformation was then performed to obtain the radial structure functions (RSF) in R-space. Final fitting of the spectra was done on Fourier transformed $k^{3}$ weighted spectra in R-space (A). The experimental spectra were fitted with single-scattering theoretical phase shift and amplitude functions calculated with the $\mathrm{ab}$ initio computer code FEFF $6^{24}$ using hypothetical atomic clusters that were generated by replacing the $\mathrm{Fe}$ atom in scorodite $\left(\mathrm{FeAsO}_{4} \cdot 2 \mathrm{H}_{2} \mathrm{O}\right)$ by $\mathrm{Ag}$. The many-body amplitude reduction factor $\left(\mathrm{S}_{0}{ }^{2}\right)$ was fixed at 0.9 . Each spectrum was fit by first isolating and fitting the first-shell As-O to estimate $\Delta E_{0}$, the difference in threshold energy between theory and experiment, by fixing the Debye-Waller parameter $\left(\sigma^{2}\right)$ at 0 and coordination numbers $(\mathrm{CN})$ at 4 for $\mathrm{As}(\mathrm{V})$. Then, $\Delta E_{0}$ was fixed at the best-fit value from first-shell fitting. The $\mathrm{CN}$ of $\mathrm{As}-\mathrm{O}$ and As-Ag, As-Ca was initially fixed to obtain estimated values for interatomic distances $(R)$ and $\sigma^{2}$. Finally, the spectrum was fitted using estimated values for $\mathrm{CN}, R$, and $\sigma^{2}$ as starting values. Error estimates of the fitted parameters were as follows: $\mathrm{CN}, \pm 20 \% ; R, \pm 0.02 \AA$; and $\sigma^{2}, \pm 20-30 \%$.

\section{RESULTS AND DISCUSSION}

Characterization of Ag Nanofilm. The AFM image in Figure 1 shows that the $\mathrm{Ag}$ nanofilm consisted of $\mathrm{Ag}$ nano islands of $40-75 \mathrm{~nm}$ in height and $50-150 \mathrm{~nm}$ in lateral size. ${ }^{4}$ Figure S1 of the Supporting Information shows the X-ray photoelectron spectroscopy (XPS) spectra of Ag nanofilm. The atomic concentrations of the elements detected were as follows: $15.1 \% \mathrm{C}, 0.5 \% \mathrm{~N}$, $46.2 \% \mathrm{O}, 2.2 \% \mathrm{Na}, 10.3 \% \mathrm{Si}, 1.6 \% \mathrm{P}$, and $24.0 \% \mathrm{Ag}$. The surface species detected on the $\mathrm{Ag}$ nanofilm included silicates, $\mathrm{Na}^{+}, \mathrm{Ag}^{\circ}$, $\mathrm{PO}_{4}{ }^{3-}$, hydrocarbons, $\mathrm{C}-\mathrm{O}, \mathrm{C}=\mathrm{O}$, and $\mathrm{O}-\mathrm{C}=\mathrm{O}$. The insets in Figure S1 of the Supporting Information show the $\mathrm{Ag} 3 \mathrm{~d}$ (Ag 3d5/ $2366.8 \mathrm{eV}$ ) and $\mathrm{Ag} \mathrm{MNN}$ peak position. The Auger parameter was $726.2 \mathrm{eV}$. Silver was mainly in the metallic $\mathrm{Ag}^{\circ}$ oxidation state on the nanofilm. The $\mathrm{PO}_{4}{ }^{3-}$ could be adsorbed on the nanofilm and could also form $\mathrm{Ag}_{3} \mathrm{PO}_{4}$ precipitates. The XPS results also indicated that some glucose or/and its oxidized derivatives were adsorbed on the nanofilm. The surface organic compounds and phosphate might protect the Ag nanofilm from oxidation because the substrate had no obvious sensitivity loss during six months of storage. 

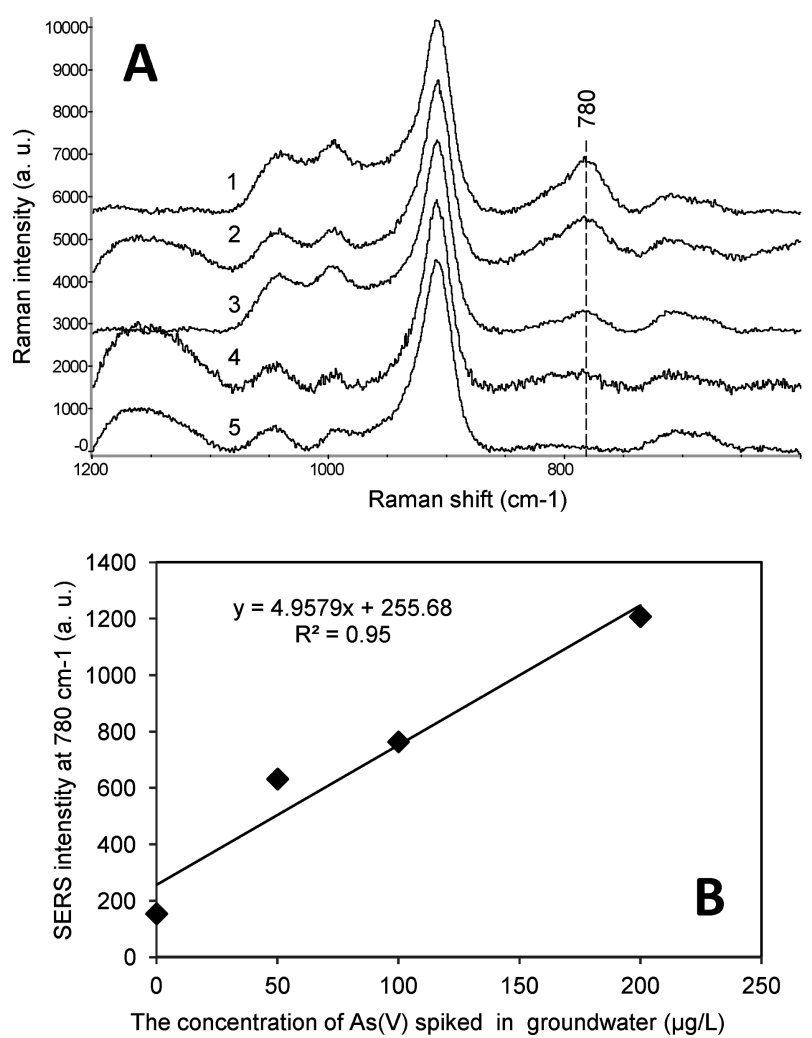

Figure 2. (A) SERS of As $(\mathrm{V})$ spiked in groundwater; spectra 1-4 are for samples of 200, 100, 50, $0 \mu \mathrm{g} / \mathrm{L} \mathrm{As}(\mathrm{V})$ spiked into the groundwater sample $(1 \mathrm{~mL})$, which were then combined with $0.35 \mathrm{~mL}$ of $1 \mathrm{~mol} / \mathrm{L}$ $\mathrm{NaF}$ solution; spectrum 5 is for the groundwater sample without $\mathrm{NaF}$. (B) SERS intensity of the $\mathrm{As}(\mathrm{V})$ band at $780 \mathrm{~cm}^{-1}$ against its concentration in groundwater.

SERS Analysis of $\mathrm{As}(\mathrm{V})$ in Groundwater. Our previous study ${ }^{4}$ showed that the Ag nanofilm could be used to detect As(V) and As(III) at $10 \mu \mathrm{g}$ As/L in DI water solutions. To study the applicability of the SERS technology for analysis of $\mathrm{As}(\mathrm{V})$ in natural waters, a groundwater sample was collected in northern New Jersey, USA, for SERS study. The characteristics of the groundwater are listed in Table S1 of the Supporting Information. As $(\mathrm{V})$ in the groundwater was $68.6 \mu \mathrm{g} / \mathrm{L}$. The SERS spectrum (line 5) in Figure 2A showed no As(V) band at $780 \mathrm{~cm}^{-1}$. Further analysis indicated the method could even not detect $10 \mathrm{mg}$ As/L As(V) spiked into the groundwater due to effect of solutes in the water (data not presented here).

We discovered that $\mathrm{F}^{-}$could be used to increase the SERS sensitivity of As (V) in the groundwater sample. When $0.35 \mathrm{~mL}$ of $1 \mathrm{~mol} / \mathrm{L} \mathrm{NaF}$ solution was mixed with $1 \mathrm{~mL}$ of the groundwater sample, the As(V) band could be detected in the SERS spectrum 4 in Figure 2A. A standard addition method was used to determine the $\mathrm{As}(\mathrm{V})$ concentration in the sample with the addition of $\mathrm{F}^{-}$. Spectra $1-3$ in Figure $2 \mathrm{~A}$ are for the samples with addition of 200,100, and $50 \mu \mathrm{g} / \mathrm{L} \mathrm{As}(\mathrm{V})$. When the intensities of the SERS As (V) band were plotted as a function of spiked As(V) concentrations, a relatively good linear line was obtained (Figure 2B). As $(\mathrm{V})$ concentration was determined to be $51.6 \mu \mathrm{g} / \mathrm{L}$ using the standard addition method. Compared to the As $(\mathrm{V})$ concentration at $68.6 \mu \mathrm{g} / \mathrm{L}$ determined with GAAS, the error of the SERS analysis was $24.7 \%$.
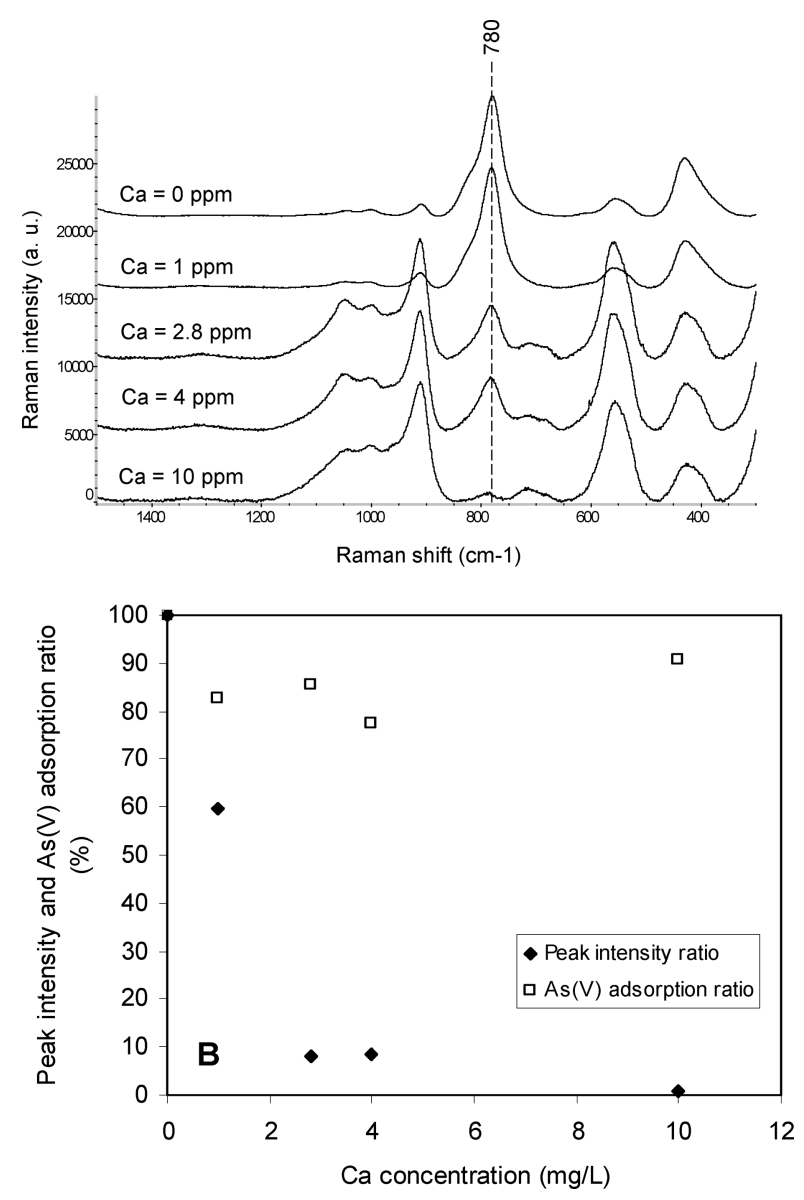

Figure 3. (A) SERS spectra of $\mathrm{As}(\mathrm{V})$ at high $\mathrm{As}(\mathrm{V})$ and $\mathrm{Ca}^{2+}$ concentrations, $5 \mathrm{mg} / \mathrm{L} \mathrm{As}(\mathrm{V})$ combined with $0,1,2.8$, 4, and $10 \mathrm{mg} / \mathrm{L} \mathrm{Ca}^{2+}, \mathrm{pH}=$ $6.0 \pm 0.2$. Spectra are scaled for clarity (spectra are offset in full scale mode). (B) As(V) SERS peak intensity ratio and As(V) adsorption ratio versus the initial $\mathrm{Ca}^{2+}$ concentration in solution.

The beneficial effect of $\mathrm{F}^{-}$on the SERS detection of As(V) was investigated using solutions containing $100 \mu \mathrm{g} / \mathrm{L} \mathrm{As}(\mathrm{V})$ and $100 \mathrm{mg} / \mathrm{L} \mathrm{Ca}^{2+}$ or $\mathrm{Mg}^{2+}$. The SERS spectra in Figure S2A of the Supporting Information showed that both $\mathrm{Ca}^{2+}$ and $\mathrm{Mg}^{2+}$ quenched the SERS As(V) band and the addition of $100 \mathrm{mmol} / \mathrm{L}$ $\mathrm{NaF}$ into the solutions eliminated the negative effect of the cations. Thermodynamic calculations indicated that $\mathrm{F}^{-}$could form precipitates with $\mathrm{Ca}^{2+}$ and $\mathrm{Mg}^{2+}$ thus eliminating their effect on SERS analysis of As(V) (Supporting Information, Figure S2B).

$\mathrm{Ca}^{2+}$ Effect on SERS Analysis of As(V). Figure 3A illustrates the effects of $\mathrm{Ca}^{2+}$ on SERS spectra of As(V). When the $\mathrm{Ca}^{2+}$ concentration increased from 0 to $4 \mathrm{mg} / \mathrm{L}$ in solutions containing $5 \mathrm{mg} / \mathrm{L} \mathrm{As}(\mathrm{V})$, the intensity of the As $(\mathrm{V})$ band at $780 \mathrm{~cm}^{-1}$ clearly decreased. When the $\mathrm{Ca}^{2+}$ concentration was $10 \mathrm{mg} / \mathrm{L}$, the intensity of the As $(\mathrm{V})$ band was significantly suppressed, and the band position shifted from 780 to $790 \mathrm{~cm}^{-1}$. The $\mathrm{pH}$ of all $\mathrm{As}(\mathrm{V})$ and $\mathrm{As}(\mathrm{V})-\mathrm{Ca}$ solutions was controlled at $6.0 \pm 0.2$ to prevent any shift in the band position caused by $\mathrm{pH}$ variation. ${ }^{21}$ The band shift in the SERS spectra implied that $\mathrm{Ca}^{2+}$ interacted with $\mathrm{As}(\mathrm{V})$ or perturbed the interaction between $\mathrm{As}(\mathrm{V})$ and the Ag nanofilm.

Previous experimental results showed that when a $1 \mathrm{~mol} / \mathrm{L}$ solution of sodium arsenate was mixed with a $1 \mathrm{~mol} / \mathrm{L}$ calcium nitrate solution at an $\mathrm{As}(\mathrm{V}) / \mathrm{Ca}$ molar ratio of 0.5 , a calcium 

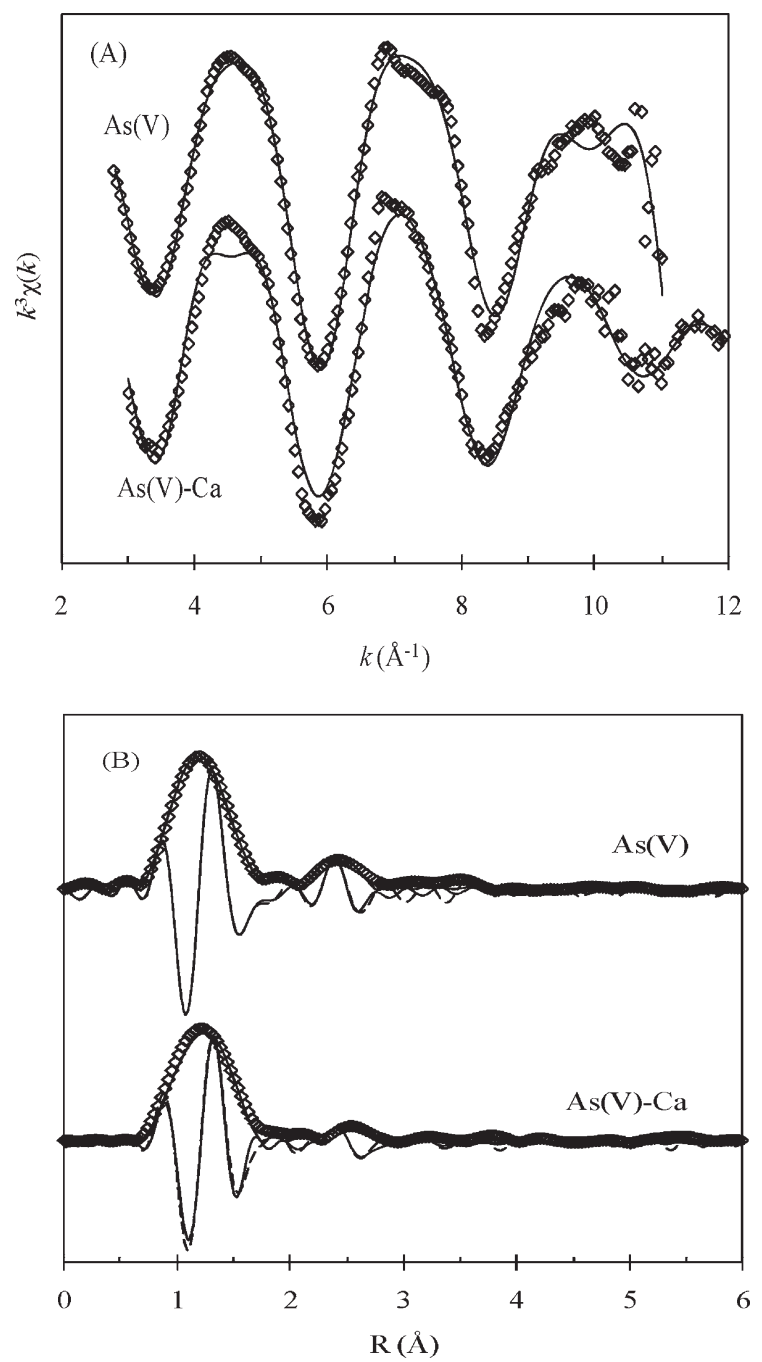

Figure 4. Normalized $K^{3}$-weighted observed (data points) and modelcalculated (solid line) As K-edge EXAFS spectra (A), and the corresponding magnitude (data points) and real parts (dashed line) of Fourier transform (B, $x$ axis not corrected for phase shifts) for adsorbed $\mathrm{As}(\mathrm{V})$ and $\mathrm{As}(\mathrm{V})-\mathrm{Ca}$ on silver nanofilm.

arsenate precipitate was formed. ${ }^{4}$ The As(V) normal Raman band was shifted from 836 to $853 \mathrm{~cm}^{-1}$, and the band intensity was suppressed dramatically. The Ca effect was attributed to the formation of the $\mathrm{Ca}_{3}\left(\mathrm{AsO}_{4}\right)_{2}$ precipitate. However, thermodynamic calculations based on a $K_{\mathrm{sp}}=6.8 \times 10^{-19}$ for $\mathrm{Ca}_{3^{-}}$ $\left(\mathrm{AsO}_{4}\right)_{2}{ }^{25}$ predicted that the precipitate should not be formed in the SERS analysis solution containing $5 \mathrm{mg} / \mathrm{L} \mathrm{As}(\mathrm{V})$ and $10 \mathrm{mg} / \mathrm{L} \mathrm{Ca}^{2+}$. In addition, the much higher sensitivity and distinct position of the As $(\mathrm{V})$ band at $790 \mathrm{~cm}^{-1}$ in Figure 3A, compared to that of the normal Raman As $(\mathrm{V})$ band, certainly indicated that the $790 \mathrm{~cm}^{-1}$ band was generated by adsorbed As $(\mathrm{V})$ on the Ag nanofilm.

The effect of $\mathrm{Ca}^{2+}$ on $\mathrm{As}(\mathrm{V})$ adsorption by the $\mathrm{Ag}$ nanofilm and on the intensity of the SERS band was compared in Figure $3 \mathrm{~B}$ to further delineate the mechanism of the $\mathrm{Ca}^{2+}$ effect. The peak intensity and $\mathrm{As}(\mathrm{V})$ adsorption ratio on the $y$ axis was calculated by dividing the intensities of the $\mathrm{As}(\mathrm{V})$ band and amounts of $\mathrm{As}(\mathrm{V})$ adsorbed at different initial Ca concentrations by the corresponding values at zero $\mathrm{Ca}^{2+}$ concentration.
Table 1. Arsenic K-edge EXAFS Fitting Results of As(V) and As(V)-Ca on Ag Nanofilm

$\begin{array}{llrrrc} & \text { shell } & R(\AA)^{a} & \mathrm{CN}^{b} & \sigma^{2}\left(\AA^{2}\right)^{c} & \text { R-factor }^{d} \\ \text { As }(\mathrm{V}) \text { system } & \text { As-O } & 1.72 & 3.8 & 0.007 & 0.010 \\ & \text { As-Ag } & 2.56 & 2.2 & 0.013 & \\ \text { As }(\mathrm{V}) \text {-Ca binary system } & \text { As-O } & 1.69 & 4.4 & 0.007 & 0.029 \\ & \text { As-Ca } & 2.97 & 2.2 & 0.019 & \\ & \text { As-Ag } & 3.03 & 0.8 & 0.023 & \end{array}$

${ }^{a}$ Interatomic distances corrected for backscatterer phase shifts. ${ }^{b}$ Average coordination number of backscatterers. ${ }^{c}$ The Debye-Waller disorder parameter. ${ }^{d} \mathrm{~A}$ goodness of fit parameter. Error estimates of the fitted parameters were as follows: $\mathrm{CN}= \pm 20 \% ; R= \pm 0.02 \AA$; and $\sigma^{2}=$ $\pm 20-30 \%$.

The As(V) SERS peak intensity ratio decreased from $100 \%$ to $0.7 \%$ when the $\mathrm{Ca}^{2+}$ concentration increased from 0 to $10 \mathrm{mg} / \mathrm{L}$. However, $\mathrm{Ca}^{2+}$ did not have much effect on the adsorption of $\mathrm{As}(\mathrm{V})$. Without $\mathrm{Ca}^{2+}$ in solution, $2.9 \mathrm{mg} / \mathrm{L}$ of As $(\mathrm{V})$ was adsorbed on $\mathrm{Ag}$ nanofilm. The presence of $1-10 \mathrm{mg} / \mathrm{L}$ of $\mathrm{Ca}^{2+}$ reduced As (V) adsorption by less than $20 \%$. The results indicated that the decreased $\mathrm{As}(\mathrm{V})$ adsorption should not contribute much to the decreased peak intensity of the As(V) SERS band.

As(V)-Ag Bonding Structures Revealed by EXAFS. The bonding structures of the adsorbed $\mathrm{As}(\mathrm{V})$ on the Ag nanofilm were analyzed using EXAFS. Figure $4 \mathrm{~A}$ and $\mathrm{B}$ are As K-edge EXAFS spectra and the corresponding magnitude (data points) and real parts (dashed line) of the Fourier transformed spectra ( $x$ axis not corrected for phase shifts). The spectra labeled As(V) and $\mathrm{As}(\mathrm{V})-\mathrm{Ca}$ were obtained for single $\mathrm{As}(\mathrm{V})$ and $\mathrm{As}(\mathrm{V})-\mathrm{Ca}$ binary adsorbates on Ag nanofilm, respectively. The solid lines were best-fit results obtained by modeling the experimental data. The two major peaks at about 1.2 and $2.3 \AA$ in the Fourier transform (data points labeled $\mathrm{As}(\mathrm{V})$ in Figure 4B) were generated by backscattering neighbor atoms in the first and second coordination shells around the centrally excited arsenic atom. It is known that four oxygen atoms are bound to an As atom in the first shell of $\mathrm{AsO}_{4}{ }^{3-}$. The best-fit modeling calculations determined that $\mathrm{Ag}$ was associated with $\mathrm{AsO}_{4}{ }^{3-}$ in the second shell with an average $\mathrm{CN}$ of 2.2 and an average As- $\mathrm{Ag}$ bond distance of $2.56 \AA$ (Table 1). Thus, As (V) was adsorbed on the $\mathrm{Ag}$ nanofilm through the formation of bidentate binuclear surface complexes, $(\mathrm{AgO})_{2} \mathrm{AsO}_{2}{ }^{-}$, as illustrated in Figure 5 (left). The formation of an inner-sphere surface complex caused a large shift in the position of the SERS As (V) band, compared to the positions of the normal Raman bands of soluble As(V) (Supporting Information, Figure S3). Furthermore, the bonding of an $\mathrm{As}(\mathrm{V})$ to two silver atoms enhanced the deprotonation of arsenate to form negatively charged surface species. The formation of an inner sphere surface complex resulted in a SERS enhancement of about $10^{6} .4$ Close attachment of analytes to nanostructured surfaces on SERS substrates is critical for achievement of extremely high sensitivity of analysis.

The presence of $\mathrm{Ca}^{2+}$ resulted in a shift in the position of the second peak (data points labeled As $(\mathrm{V})-\mathrm{Ca}$ in Figure 4B) to $2.5 \AA$, compared to the As $(V)$ system. Modeling calculations determined that the second-shell peak was generated by both $\mathrm{Ag}$ and $\mathrm{Ca}$ atoms. The average $\mathrm{CN}$ of $\mathrm{Ag}$ and $\mathrm{Ca}$ was 0.8 and 2.2, respectively (Table 1 ). The bond distance was 3.03 and 2.97 between As-Ag and As-Ca, respectively. Thus, an adsorbed $\mathrm{As}(\mathrm{V})$ formed inner-sphere surface complexes with a Ag and two 


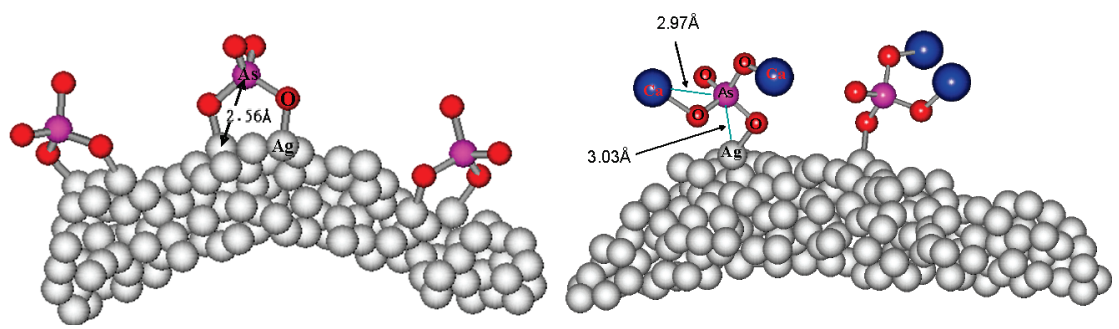

Figure 5. Bonding structures of $\mathrm{AsO}_{4}{ }^{3-}$ with silver atoms on silver nanofilm constructed based on the EXAFS data.

Ca atoms on the Ag nanofilm as illustrated in Figure 5(right). $\mathrm{Ca}^{2+}$ competed with $\mathrm{Ag}$ surface sites for binding with $\mathrm{As}(\mathrm{V})$ and weakened the bonding strength between $\mathrm{As}(\mathrm{V})$ and $\mathrm{Ag}$. The increased $\mathrm{As}-\mathrm{Ag}$ bond distance and the reduced number of bonds between As and Ag reduced the EM and CE enhancements. By changing the bonding structure of $\mathrm{As}(\mathrm{V})$ with silver, $\mathrm{Ca}^{2+}$ may have changed the energy difference between the highest occupied energy level (HOMO) of the Ag islands and the lowest unoccupied energy level (LUMO) of the As(V) and inhibited the charge transfer process. ${ }^{26,27}$

\section{CONCLUSIONS}

This study investigated the interactions between $\mathrm{As}(\mathrm{V})$ and the Ag nanofilm through the effects of $\mathrm{Ca}^{2+}$ on SERS bands of $\mathrm{As}(\mathrm{V})$. It demonstrated that EXAFS is a powerful surface analysis technique to directly determine the bonding structures of analytes on SERS-active substrates. The EXAFS analysis and SERS spectra obtained at different $\mathrm{Ca}^{2+}$ concentrations consistently indicated that $\mathrm{As}(\mathrm{V})$ formed inner-sphere complexes with $\mathrm{Ag}$ atoms on the $\mathrm{Ag}$ nanofilm.

\section{ASSOCIATED CONTENT}

S Supporting Information. XPS spectra of Ag nanofilm, characteristics of groundwater, fluoride effect on the SERS of $\mathrm{As}(\mathrm{V})$ in the presence of $\mathrm{Ca}^{2+}$ and $\mathrm{Mg}^{2+}$, and $\mathrm{pH}$ effect on SERS of As $(\mathrm{V})$. This material is available free of charge via the Internet at http://pubs.acs.org.

\section{AUTHOR INFORMATION}

\section{Corresponding Author}

*Phone: +1 201 2168014; Fax: +1 201 2188303; E-mail: xmeng@ stevens.edu.

\section{REFERENCES}

(1) Ng, J. C.; Wang, J. P.; Shraim, A. Chemosphere 2003, 52, 1353-1359.

(2) Cullum, B. M.; Mobley, J.; Chi, Z. H.; Stokes, D.; Miller, G. H.; Vo-Dinh, T. Rev. Sci. Instrum. 2000, 71, 1602-1607.

(3) Mulvihill, M.; Tao, A.; Benjauthrit, K.; Arnold, J.; Yang, P. D. Angew. Chem., Int. Ed. 2008, 47, 6456-6460.

(4) Xu, Z.; Hao, J.; Li, F.; Meng, X. J. Colloid Interface Sci. 2010, 347, 90-95.

(5) Kneipp, K.; Wang, Y.; Kneipp, H.; Perelman, L. T.; Itzkan, I.; Dasari, R. R.; Feld, M. S. Phys. Rev. Lett. 1997, 78, 1667-1670.

(6) Nie, S.; Emory, S. R. Science 1997, 275, 1102-1106.

(7) Moskovits, M. Rev. Mod. Phys. 1985, 57, 783-826.

(8) Otto, A.; Mrozek, I.; Grabhorn, H.; Akemann, W. J. Phys. Condens. Matter 1992, 4, 1143-1212.
(9) Andrade, G. F. S.; Temperini, M. L. A. J. Raman Spectrosc. 2009, 40, 1989-1995.

(10) Wu, D. Y.; Liu, X. M.; Duan, S.; Xu, X.; Ren, B.; Lin, S. H.; Tian, Z. Q. J. Phys. Chem. C 2008, 112, 4195-4204.

(11) Zhang, X.; Zhao, J.; Whitney, A.; Elam, J.; VanDuyne, R. J. Am. Chem. Soc. 2006, 128, 10304-10309.

(12) Bryant, M. A.; Pemberton, J. E. J. Am. Chem. Soc. 1991, 113, 8284-8293.

(13) Maitani, M. M.; Ohlberg, D. A. A.; Li, Z.; Allara, D. L.; Stewart, D. R.; Williams, R. S. J. Am. Chem. Soc. 2009, 131, 6310-6311.

(14) Campion, A.; Kambhampati, P. Chem. Soc. Rev. 1998, 27, 241-250.

(15) Zhou, Q.; Fan, Q.; Zhuang, Y.; Li, Y.; Zhao, G.; Zheng, J. J. Phys. Chem. B 2006, 110, 12029-12033.

(16) Tian, Z. Q.; Ren, B.; Wu, D. Y. J. Phys. Chem. B 2002, 106, 9463-9483.

(17) Peyser-Capadona, L.; Zheng, J.; Gonzalez, J. I.; Lee, T. H.; Patel, S. A.; Dickson, R. M. Phys. Rev. Lett. 2005, 94, 058301-058304.

(18) Waychunas, G. A.; Rea, B. A.; Fuller, C. C.; Davis, J. A. Geochim. Cosmochim. Acta 1993, 57, 2251-2269.

(19) Fendorf, S.; Elck, M. J.; Grossl, P.; Sparks, D. L. Environ. Sci. Technol. 1997, 31, 315-320.

(20) Ona-Nguema, G.; Morin, G.; Juillot, F.; Calas, G.; Brown, G. E., Jr. Environ. Sci. Technol. 2005, 39, 9147-9155.

(21) Pena, M.; Meng, X. G.; Korfiatis, G. P.; Jing, C. Y. Environ. Sci. Technol. 2006, 40, 1257-1262.

(22) Newville, M. J. Synchrotron Radiat. 2001, 8, 322-324.

(23) Jing, C.; Liu, S.; Patel, M.; Meng, X. Environ. Sci. Technol. 2005, 39, 5481-5487.

(24) Mustre de Leon, J.; Rehr, J. J.; Zabinsky, S. I.; Albers, R. C. Phys. Rev. B 1991, 44, 4146-4156.

(25) Lee, C. C.; Lin, S. D. Handbook of Environmental Engineering Calculations; McGraw-Hill Professional: New York, 2000.

(26) Morton, S. M.; Jensen, L. J. Am. Chem. Soc. 2009, 131, 4090-4098.

(27) Arenas, J. F.; Soto, J.; Pelaez, D.; Fernandez, D. J.; Otero, J. C. Int. J. Quantum Chem. 2005, 104, 681-694. 